\title{
A Preliminary Study on Genetic Variation of Arsenic Concentration in 32 Different Genotypes of Leafy Vegetable
}

\author{
Mathieu Nsenga Kumwimba ${ }^{1}$, Xibai Zeng ${ }^{1}$, Lingyu Bai $^{1} \&$ Jinjin Wang ${ }^{1}$ \\ ${ }^{1}$ Institute of Environment and Sustainable Development in Agriculture, Chinese Academy of Agricultural \\ Sciences / Key Laboratory of Agro-Environment, Ministry of Agriculture, Beijing, China
}

Correspondence: Zeng Xibai, Chinese Academy of Agricultural Sciences, Beijing 100081, China. Tel: 86-10-8210-6009. E-mail: zengxb@ieda.org.cn

$\begin{array}{lc}\text { Received: October 17, } 2013 & \text { Accepted: October 31, } 2013 \quad \text { Online Published: June 28, } 2014 \\ \text { doi:10.5539/ep.v3n3p72 } & \text { URL: http://dx.doi.org/10.5539/ep.v3n3p72 }\end{array}$

\begin{abstract}
Leafy vegetables are a food crop with higher protein and are also important source of minerals which are essential for good health. Due to the large consumption, it is necessary to decrease the arsenic (As) concentration in leafy vegetable to avoid the potential risk to human health. The current study is aimed at assessing arsenic (As) accumulation ability and identification of cultivars with less As concentration that could be grown in As contaminated farmland for food safety. A set of thirty two leafy vegetable cultivars from 5 species were

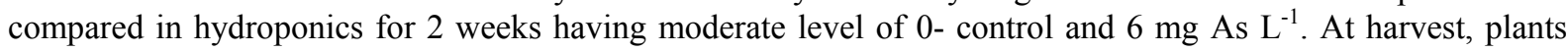
were sampled and analyzed for As concentration. Significant genotypic variations were observed in the shoots As concentration, translocation and bioaccumulation factors revealing more than 8 and 25 times cultivar differences in shoot As concentration, and in translocation factors respectively. This result revealed that As concentration in shoot was in part governed by the greater ability of root-shoot translocation. Cultivar Sijibaiye (SJBY) had the lowest shoot As concentration while the highest was detected in Dayekongxincai (DYKXC). The average As concentration in roots were found to be ten to twenty times higher than those observed in shoots, indicating that there is restricted transport of As from the root system to the shoot of cultivars. Therefore, it has been suggested that there is possibility to lower the As concentration in leafy vegetables by selecting and breeding cultivars with less As concentration that can be safely grown in contaminated soils with the slight and moderate levels of As for safe consumption.
\end{abstract}

Keywords: arsenic (V), leafy vegetable, hydroponic screening, accumulation, cultivar variation

\section{Introduction}

Industrial activities such as mining, the disposal of industrial and municipal wastes in agricultural lands, excess use of fertilizers and pesticides have contaminated the large areas of agricultural soils with arsenic (As) in many countries (McGrath et al.2001). These pollutants are especially harmful where vegetables are grown in contaminated soils, which not only reduce the plant growth but also cause health hazards to the human beings as well as animals. Islam et al. (2007) reported that crop species are regulated by genetic basis for heavy metal transport and accumulation. However, the toxic effects of As may cause high susceptibility in some cultivars than others. The genotypic variation in the different cultivars for arsenic concentration, as a strategy to reduce the movement of As from contaminated soils to edible parts of crop plants has been receiving close attention (Norton et al., 2012). Researchers have developed the arsenic stress toxicity tolerant rice cultivars through locally-grown rice cultivars in Bangladesh, India and China (Norton et al., 2009). This will give a long-term effective and economical means of reducing As contamination in vegetables. Moreover, the fundamental requirement for breeding low As-accumulation cultivars is to know the genotypic differences and the mechanisms governing As accumulation in crops. Zia et al. (2011) found substantial genotypic variation in rice As accumulation, suggesting that genetic factors determined differences in As accumulation. Consequently, genetic variation in plants for uptake and translocation of As provides the potentiality to develop the cultivars with reduced dietary exposure to arsenic which either assimilates less As or restrict As translocation (Meharg et al., 2002). As the arsenic cannot be removed from the contaminated soils, therefore, there is a need to develop locally adapted leafy vegetable cultivars which have less arsenic accumulation. The uptake and translocation of As in plants vary greatly not only among plant species but also among cultivars within the same species, thus, an 
effective way to face this problem is growing of more As-excluder vegetable cultivars. The objectives of this study were (1) to screen and identify the cultivars with less As concentrations that can be grown in As contaminated farmland for food safety, (2) and also to obtain information on the basis of their genetic variation in the shoots As concentration.

\section{Materials and methods}

\subsection{Plant Material and Preparation of Seedlings}

Seeds of 32 cultivars of leafy vegetable belonging to 5 species including Romaine (Lactuce Sativa var. longifolia), Lettuce (Lactuce Sativa), Celery (Apium graveolens L.), and water spinach (Ipomea aquatica) (Table 1) were purchased from Chinese Academy of Agricultural Sciences, Beijing P. R. China and were cultivated at Institute of Environment and Sustainable Development in Agriculture, Beijing, China in 2012. The seeds were surface sterilized with $30 \% \mathrm{H}_{2} \mathrm{O}_{2}$ for $15 \mathrm{~min}$, rinsed five times with distilled water were sown in plates containing autoclaved vermiculite. On the $7^{\text {th }}$ day, at third leaf stage, the healthy and uniform sized seedlings were carefully removed from vermiculite, and washed with distilled water then transferred to hydroponic bottles each containing $1500 \mathrm{ml}$ of full-strength of modified Hoagland and Arnon with $\mathrm{pH}$ adjusted to 6.3 by using $\mathrm{NaOH}$ or $\mathrm{HCl}$ for 10 days. Nutrient solution was renewed twice a week.

\subsection{Hydroponic Screening}

On the $21^{\text {st }}$ day of transplant to the hydroponic bottles, the As in the form of $\mathrm{As}(\mathrm{V}) \mathrm{Na}_{3} \mathrm{AsO}_{4} \cdot 12 \mathrm{H}_{2} \mathrm{O}$ was applied at the concentration of 0 - control and $6 \mathrm{mg} \mathrm{As} \mathrm{L}^{-1}$ as the treatment in the basic nutrient solution for 14 days. There were four replicates for each cultivar and each replicate comprises four plants. The As treated nutrient solution was renewed once a week. Plants were grown in hydroponic bottles for 35 days, and then harvested. The shoots and roots of all harvested plants were separated carefully, washed with water, and then rinsed several times using deionizised water to remove adhering particles. These samples of roots and shoots were gently packed in envelopes. The concentration of As in cultivars was determined using Atomic Fluorescence Spectrometry (AFS) following the procedure described by Smith et al. (2009). Statistical analysis was performed by using SPSS software version 16.0 and Sigma Plot 10.0.

\subsection{Kinetics of $A s(V)$ uptake}

After 4 weeks of growth before the uptake experiment, the seedlings were transferred to the deionized water for 5 days, and then uniform seedlings from TXYLS and SJBY were selected washed from root system and transferred to plastic bottles containing $1200 \mathrm{ml}$ of As uptake solution. Each bottle was wrapped with opaque plastic membrane. Eight different concentrations of arsenic $\left(0,0.5,1,2,4,6,8\right.$, and $\left.10 \mathrm{mg} \mathrm{L}^{-1}\right)$ were used to study the uptake kinetics of arsenic. Each treatment was replicated three times. Each 1200-mL container had 4 plants. The $\mathrm{pH}$ of the nutrient solution was maintained at 6.3 . At each time interval $(0,0.5,1,2,4,6,8,10,12$, 22 , and $24 \mathrm{~h}$ ), sample of $1 \mathrm{ml}$ was withdrawn from each uptake solution to measure depletion in As, as a result of its uptake by plants, the depletion period was for $24 \mathrm{~h}$. Water losses through transpiration and absorption were compensated by additions of deionized water at hourly intervals. After $24 \mathrm{~h}$ of uptake experiment, the plants were harvested and quickly rinsed with distilled water. The plants were separated into roots and shoots, blotted dry with paper tissue and dried at $65^{\circ} \mathrm{C}$ for $72 \mathrm{~h}$, and the dry weights were recorded. Arsenic concentrations were determined as previously described.

\subsection{Calculations of As Uptake Rates and Kinetic Parameters}

The amount of uptake rate ( $\mathrm{V}\left[\mathrm{mg} \mathrm{As} \mathrm{g}^{-1}\right.$ shoot d.wt.hr $\left.{ }^{-1}\right]$ ) was calculated from the depletion of As in the uptake solution. As uptake by the plant per unit time per gram dry weight was calculated according to the following formula: (Ajaelu et al., 2011).

$$
\mathrm{V}=\frac{(V i \times C i)-(V f \times C f)}{t \times B d w t}
$$

Where Vi, Ci Vf, Cf and B d.wt are the volumes (V) and quantities in $\mathrm{mg} / \mathrm{L}$ of substrate in solution at the start and the end of uptake experiment, and $t$ is the time in hours and $\mathrm{B}$ dwt is the biomass dry weight of the plants, respectively. The reduction in the volume was very small, so this was not taken into account in the calculation.

The Michaelis-Menten Equation is:

$$
V_{0}=\frac{V_{\max }[S]}{K_{m}+[S]}
$$


Where

$\mathrm{V}_{0}$ : is the initial velocity of the reaction at substrate concentrations (S)

[S]: is the substrate concentration

Vmax: is the maximum uptake rate $\left(\mathrm{mgAsg}^{-1}\right.$ shoot d.wt.hr $\left.{ }^{-1}\right)$ achieved at which the enzyme is saturated with substrate

$\mathrm{Km}: \quad$ is the Michaelis-Menten constant

The parameters $\mathrm{Km}$ and Vmax characterize the ability of plant to absorb nutrients from their soil environment [8]. The equation describes the relationship between the uptake rate of the nutrient and the nutrient concentration. Uptake rate reaches a constant or saturated rate (Vmax) at high ambient concentration. Lineweaver \&Burk (1998)] pointed out that equation (2) becomes linear in form upon taking the reciprocal of both sides of the equation to calculate the key parameters in the Michaelis-Menten equation:

$$
\begin{aligned}
& V_{0}=\frac{V_{\max }[S]}{K_{m}+[S]} \rightarrow\left(\frac{1}{V}\right)=\left(\frac{K_{m}}{V_{\max }}\right) \cdot\left(\frac{1}{S}\right)+\left(\frac{1}{V_{\max }}\right) \\
& \text { i.e. }(\mathrm{y}=\mathrm{m} \mathrm{x}+\mathrm{c}) \text {, where }(\mathrm{y}=1 / \mathrm{V} \text { and } \mathrm{x}=1 /[\mathrm{s}])
\end{aligned}
$$

In order to obtain the kinetic uptake parameters representing the maximum uptake rate (Vmax) and the half saturation constant $(\mathrm{Km})$, by plotting $1 / \mathrm{V}$ against $1 /[\mathrm{S}]$ will give a straight line graph having a slope of $\mathrm{Km} / \mathrm{Vmax}$ and a $\mathrm{y}$ - intercept on the ordinate at 1/Vmax. From this plot, the $\mathrm{Km}$ and Vmax values of arsenic uptake were determined by linear regression analysis, thus giving a convenient method for obtaining both Vmax and $\mathrm{Km}$.

\subsection{Statistical Analysis}

All data were performed using One-way analysis of variance (ANOVA), using SPSS software version 16.0 and Sigma Plot 10.0. Significant differences among data were evaluated with the least significant difference (LSD) test at a $5 \%$ probability level. The tolerance index (TI) was expressed on the basis of root and shoot biomass, calculated as the following:

$\mathrm{TI}=100 \mathrm{x}$ [biomass] As /[biomass]control

The translocation factor (TF), bioaccumulation factors $(\mathrm{BCF})$ and As accumulation in shoot were calculated as follows:

$\mathrm{TF}=[\mathrm{As}]$ shoot $/[\mathrm{As}]$ root

$\mathrm{BCF}=[\mathrm{As}]$ shoot $/[\mathrm{As}]$ nutrient culture

As accumulation in shoot $=[$ biomass $]$ shoot $\mathrm{x}[\mathrm{As}]$ shoot 
Table 1. Name, abbreviation, origin, and seed provider of 32 leafy vegetable cultivars used for hydroponic experiment

\begin{tabular}{|c|c|c|c|c|}
\hline No. & Cultivar name & Abbreviation & Origin & Seed provideı \\
\hline & Celery & \multicolumn{3}{|c|}{ Apium graveolens L. } \\
\hline 1 & Mei qin & MQ & US & IVF, CAAS \\
\hline 2 & Meiguo baili xiqin & MGBLXQ & US & IVF, CAAS \\
\hline 3 & Boli cui shi qin & BLCSQ & China & IVF, CAAS \\
\hline 4 & Meiguo wentu la xi qin & MGWLTXQ & US & IVF, CAAS \\
\hline 5 & Texuan si ji xi qin & TXSJXQ & US & IVF, CAAS \\
\hline 6 & Daye qin & DYQ & China & IVF, CAAS \\
\hline 7 & Shengjie bai qin & SJBQ & China & IVF, CAAS \\
\hline 8 & Siji xiao xiang qin & SJXXQ & Hongkong & IVF, CAAS \\
\hline 9 & Wentula qin & WTLQ & US & IVF, CAAS \\
\hline \multirow[t]{2}{*}{10} & Riben xiao xiang qin & RBXXQ & Japanese & IVF, CAAS \\
\hline & Lettuce & \multicolumn{3}{|l|}{ Lactuce Sativa } \\
\hline 11 & Texuanyanling sun & TXYLS & China & BGSRDC \\
\hline 12 & Sijibaiye & SJBY & China & BGSRDC \\
\hline 13 & Huayesun jing yong woju & HYSJYWJ & China & BGSRDC \\
\hline 14 & Yeyong woju & YYWJ & China & BGSRDC \\
\hline \multirow[t]{2}{*}{15} & Guayuanyiyesun & GYYYS & China & BGSRDC \\
\hline & Romaine & \multicolumn{3}{|c|}{ Lactuce Sativa,var. longifolia } \\
\hline 16 & Helanziye shengcai & HLZYSC & Netherlands & BGLATI \\
\hline 17 & Nanhan zixiushengcai & NHZXSC & South Korea & BGLATI \\
\hline 18 & Xingyun ruan wei & XYRW & China & BGLATI \\
\hline 19 & Dasushengcai & DSSC & US & BGLATI \\
\hline 20 & Jieqiushengcai & JQSC & China & BGLATI \\
\hline \multirow[t]{2}{*}{21} & Ziluolan & ZLL & China & BGLATI \\
\hline & Water Spinach & \multicolumn{3}{|c|}{ Ipomea aquatica } \\
\hline 22 & Chunguo kongxincai2 & CGKXC2 & China & BSVSPC \\
\hline 23 & Dayekongxincai & DYKXC & China & BSVSPC \\
\hline 24 & Chunguo kongxincai 1 & CGKXC1 & China & BSVSPC \\
\hline 25 & Jingyanye kongxincai & JYYKXC & China & BSVSPC \\
\hline \multirow[t]{2}{*}{26} & Taiguo kongxincai & TGKXC & Thailand & BSVSPC \\
\hline & Amaranth & \multicolumn{3}{|c|}{ Amaranthus mangostanus $L$. } \\
\hline 27 & Huahongxianxcai & HHXC & China & $\mathrm{BSBC}$ \\
\hline 28 & Yuanyebaixiancai & YYBXC & China & $\mathrm{BSBC}$ \\
\hline 29 & Taiwanluxiancai & TWLXC & Taiwan & BSBC \\
\hline 30 & Baiyexiancai & $\mathrm{BYXC}$ & China & $\mathrm{BSBC}$ \\
\hline 31 & Tedayehuahongxiancai & TDYHHXC & China & BSBC \\
\hline 32 & Jingxuanhongxiancai & JXHXC & China & $\mathrm{BSBC}$ \\
\hline
\end{tabular}

IVF, CAAS: The Institute of vegetable and flowers, Chinese Academy of Agricultural Sciences

BGSRDC: Beijing Gardening Seeds of Research and Development Center

BGLATI: Beijing Golden Land Agricultural Technology Institute

BSVSPC: Beijing Special Vegetable Seed and Plant Co.

BSBC: Beijing seed and breed center 


\section{Results}

\subsection{Genotypic Variations in Shoot As Concentration and Accumulation}

As it can be seen in table 2, very wide genotypic variations in the average shoot As concentrations and accumulations among 10 cultivars of celery, 6 of romaine, 5 of lettuce, 6 of amaranth and 5 of water spinach, which were tested under As treatment $\left(6 \mathrm{mg} \mathrm{L}^{-1}\right)$. Out of the 32 cultivars, As concentrations ranged from 14.07 to $112.16 \mathrm{mg} \mathrm{kg}^{-1}$ dry weight (8-fold variation). The average As concentrations in root was ten to twenty- two times higher than that in shoot (root $>$ shoot) as an indicator for translocation ability from root to shoot. Figure 1 shows the variations among vegetable species in terms of As concentrations ranging from 14.065 to $20.555,16.918$ to $27.030,21.418$ to $47.778,29.54$ to 87.51 and 91.470 to $112.160 \mathrm{mg} \mathrm{kg}^{-1}$ dry weight for Lettuce, Romaine, Amaranth, Celery and Water spinach, respectively. Lettuce was significantly lower than romaine, amaranth, celery and water spinach. There were significant genotypic differences $(\mathrm{P}<0.05)$ which accounted for $12.54 \%$ of the variation among them. The main results were shown as follows: there was a greater difference among species and different cultivars and were also significantly different in the ability to accumulate As. SJBY had the lowest shoot As concentration (14.065 $\mathrm{mg} \mathrm{kg}^{-1}$ dry weight), followed by GYYYS, HYSJYWJ, XYRW, JQSC, YYWJ, etc. While the highest shoot As concentration were detected in DYKXC (112.160 mg kg-1 dry weight), followed by JYYKXC, CGKXC 2, CGKXC 1. It was so interesting that five species could be placed into 3 groups and can be differentiated corresponding to: (a) high, (b) intermediate and (c) low arsenic. Arsenic concentrations in shoot of 5 species were found to follow the trend: Lettuce $<$ Romaine $<$ Amaranth $<$ Celery $<$ Spinach (Figure 1). Shaibur et al. (2009) reported that the specialty of water-spinach is that it accumulated higher concentrations of As in shoot without showing visible toxicity symptoms. This was very similar to what we found in this study.

\subsection{Arsenic accumulation}

The data presented in Table 2 shows the amounts of arsenic (As) accumulated in the shoot of 32 cultivars. The values are expressed in $\mu \mathrm{g}-1$ pot dry weight each calculated from the formula: (dry weight $\times$ As concentration) and they show significant different $(\mathrm{p}<0.05)$, as mentioned in Table 2 ranging from 61.79 to $188.47,30.25$ to $55.1,26.03,92.37$ to 173.21 to $51.64,16.75$ to $71.76 \mu \mathrm{g}^{-1}$ pot dry weight for celery, lettuce, romaine, water spinach and amaranth, respectively. Arsenic accumulated to the greatest extent in RBXXQ, followed by MGBLXQ, JYYKXC, CGKXC 1, CGKXC 2, etc. while the lowest shoot As accumulation was found in the TDYHHXC. 

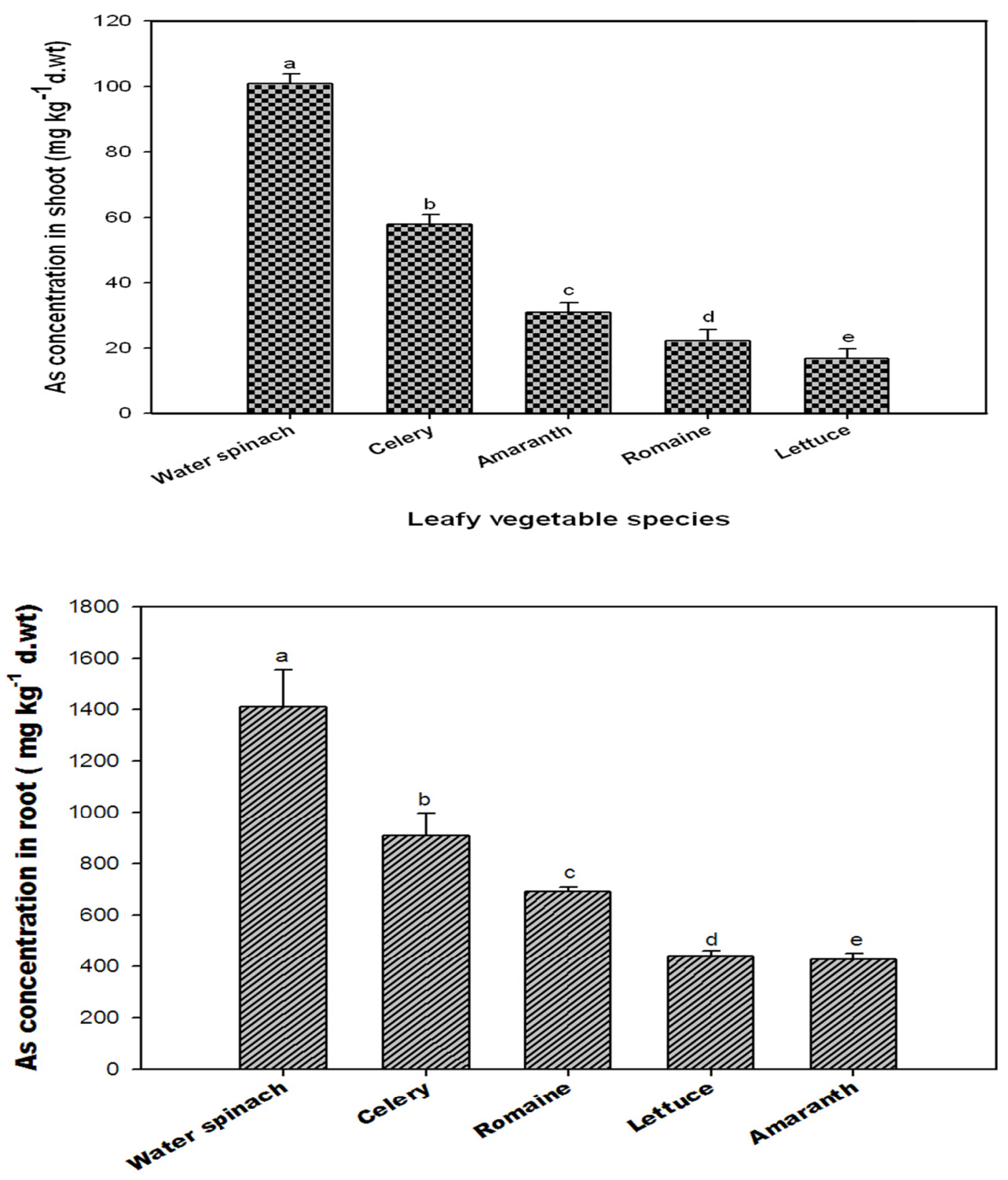

Leafy vegetable species

Figure 1. As concentration ( $\mathrm{mg} \mathrm{kg}^{-1} \mathrm{~d}$.wt) in shoot and root of 5 group of species

Values are mean $\pm \mathrm{SD}$ of the cultivars within the species. Different letters indicate significant differences at the 0.05 level based on LSD test. 
Table 2. As concentration ( $\mathrm{mg} / \mathrm{kg} \mathrm{DW})$ and accumulation $\left(\mu \mathrm{g}^{-1}\right.$ pot dry weight) of thirty two leafy vegetable cultivars.

\begin{tabular}{|c|c|c|}
\hline Cultivar & As concentration & As accumulation \\
\hline \multicolumn{3}{|l|}{ Celery } \\
\hline Mei qin & $56.51 \pm 1.70$ ef & $61.79 \pm 2.66$ fghij \\
\hline Meiguo baili xiqin & $87.51 \pm 2.22 \mathrm{c}$ & $179.75 \pm 4.51 \mathrm{a}$ \\
\hline Boli cui shi qin & $42.68 \pm 2.82 \mathrm{efgh}$ & $93.90 \pm 5.79$ ef \\
\hline Meiguo wentu la xi qin & $33.74 \pm 1.50$ ghijk & $82.81 \pm 2.94$ efg \\
\hline Texuan si ji xi qin & $61.00 \pm 8.88 \mathrm{de}$ & $93.92 \pm 14.98 \mathrm{ef}$ \\
\hline Daye qin & $29.54 \pm 1.69$ ghijk & $25.56 \pm 1.51 \mathrm{jk}$ \\
\hline Shengjie bai qin & $38.14 \pm 3.21$ fghij & $49.47 \pm 4.13$ ghijk \\
\hline Siji xiao xiang qin & $77.19 \pm 2.73 \mathrm{~cd}$ & $90.06 \pm 4.34$ ef \\
\hline Wentula qin & $77.14 \pm 2.37 \mathrm{~cd}$ & $79.82 \pm 2.65 \mathrm{efgh}$ \\
\hline Riben xiao xiang qin & $77.17 \pm 0.74 \mathrm{~cd}$ & $188.47 \pm 12.93 \mathrm{a}$ \\
\hline \multicolumn{3}{|l|}{ Lettuce } \\
\hline Texuanyanling sun & $20.56 \pm 0.83 \mathrm{ijk}$ & $55.11 \pm 2.49$ ghij \\
\hline Sijibaiye & $14.07 \pm 0.21 \mathrm{k}$ & $30.25 \pm 4.39 \mathrm{jk}$ \\
\hline Huayesun jing yong woju & $16.27 \pm 0.71 \mathrm{k}$ & $45.07 \pm 3.06$ hijk \\
\hline Yeyong woju & $17.67 \pm 0.63 \mathrm{jk}$ & $47.97 \pm 4.86$ ghijk \\
\hline Guayuanyiyesun & $16.22 \pm 0.50 \mathrm{k}$ & $40.62 \pm 1.21 \mathrm{ijk}$ \\
\hline \multicolumn{3}{|l|}{ Romaine } \\
\hline Helanziye shengcai & $27.03 \pm 0.79$ hijk & $42.40 \pm 0.98 \mathrm{ijk}$ \\
\hline Nanhan zixiushengcai & $20.47 \pm 1.35 \mathrm{ijk}$ & $31.27 \pm 2.44 \mathrm{jk}$ \\
\hline Xingyun ruan wei & $16.92 \pm 0.84 \mathrm{jk}$ & $26.03 \pm 2.67 \mathrm{jk}$ \\
\hline Dasushengcai & $25.62 \pm 0.30$ hijk & $30.46 \pm 1.37 \mathrm{jk}$ \\
\hline Jieqiushengcai & $17.74 \pm 0.71 \mathrm{jk}$ & $27.23 \pm 1.38 \mathrm{jk}$ \\
\hline Ziluolan & $25.91 \pm 0.27$ hijk & $51.64 \pm 1.86$ ghijk \\
\hline \multicolumn{3}{|l|}{ Water Spinach } \\
\hline Chunguo kongxincai2 & $96.42 \pm 2.11 \mathrm{abc}$ & $139.50 \pm 10.09 \mathrm{~cd}$ \\
\hline Dayekongxincai & $112.16 \pm 16.45 \mathrm{a}$ & $92.37 \pm 14.63$ ef \\
\hline Chunguo kongxincai 1 & $94.44 \pm 16.8 \mathrm{abc}$ & $147.84 \pm 42.06 \mathrm{bc}$ \\
\hline Jingyanye kongxincai & $110.39 \pm 19.33 \mathrm{ab}$ & $173.21 \pm 26.65 \mathrm{ab}$ \\
\hline Taiguo kongxincai & $91.47 \pm 10.37 \mathrm{bc}$ & $109.53 \pm 12.14 \mathrm{de}$ \\
\hline \multicolumn{3}{|l|}{ Amaranth } \\
\hline Huahongxianxcai & $47.78 \pm 6.76 \mathrm{efg}$ & $71.76 \pm 11.93$ fghi \\
\hline Yuanyebaixiancai & $22.63 \pm 2.23$ hijk & $25.69 \pm 2.50 \mathrm{jk}$ \\
\hline Taiwanluxiancai & $40.51 \pm 3.91 \mathrm{fghi}$ & $31.11 \pm 3.23 \mathrm{jk}$ \\
\hline Taiyexiancai & $30.59 \pm 2.92$ ghijk & $30.31 \pm 5.41 \mathrm{jk}$ \\
\hline Tedayehuahongxiancai & $22.36 \pm 1.67 \mathrm{hijk}$ & $16.75 \pm 1.27 \mathrm{k}$ \\
\hline Jingxuanhongxiancai & $21.42 \pm 1.62 \mathrm{ijk}$ & $25.15 \pm 2.32 \mathrm{jk}$ \\
\hline
\end{tabular}

Values (mean \pm S.E. $\mathrm{n}=4$ ) with different letters in the same column are significantly different according to the duncan's test $(\mathrm{P}<0.05)$ 


\subsection{Genetic Variations in Shoot Biomass Trait Under As Stress}

By growing 32 cultivars of leafy vegetable in the greenhouse, the responses of the selected cultivars differed and showed significantly differences for vegetable species $(\mathrm{P}<0.05)$ and display various plant morphological differences that are predicted to be the cause of variation in biomass production. The shoot biomass (FW) of tested cultivars varied between 6.010- 47.315 (average 26.655) $\mathrm{g} \mathrm{pot}^{-1}$ for celery cultivars, 46.340-60.505 (average 53.213) $\mathrm{g} \mathrm{pot}^{-1}$ for lettuce, 34.610-64.350 (average 48.279) $\mathrm{g} \mathrm{pot}^{-1}$ for romaine, 18.583-31.498 (average 22.29) $\mathrm{g} \mathrm{pot}^{-1}$ for water spinach and 8.353-15.590 (average 10.5) $\mathrm{g} \mathrm{pot}^{-1}$ for amaranth under $6 \mathrm{mg} \mathrm{L}^{-1}$ ( Figure 2). This suggests that shoot biomass variation due to genetic differences among plant species and with cultivars was much greater. The maximum reduction in shoot biomass was observed in DYQ (48.2\%), followed by BYXC (45\%), YYBXC (39\%), JXHXC (26.8\%), MGBLXQ (26.5\%), TGKXC (15.8\%), YYBXC (15.7), TDYHHXC (12.5\%), TXYLS (11\%), RBXXQ (10.9\%), JYYKXC (10\%), TWLXC (9.8\%), DYKXC (8.3\%), YYWJ (8.8\%), HYSJYWJ (7.6\%), WTLQ (6.7\%), SJXXQ (5.1\%), NHZXSC (5.2\%), SJBY(4.5\%) (Table 3).

The tolerance index (TI) in terms of the biomass ratio of As treatment to control was high in all cultivars except DYQ, YYBXC and BYXC. By contrast, $69 \%$ of tested cultivars in $6 \mathrm{mg} \mathrm{L}-1$ As showed a tolerance index higher than $90 \%$ (Table 3). The result suggests that shoot biomass variation due to genetic differences among cultivars was greater. MQ and CGKXC 2 cultivars had the highest shoots averaged over the level of arsenic used. Therefore, the effects of As on leafy vegetable growth and development appear to be cultivar dependent.

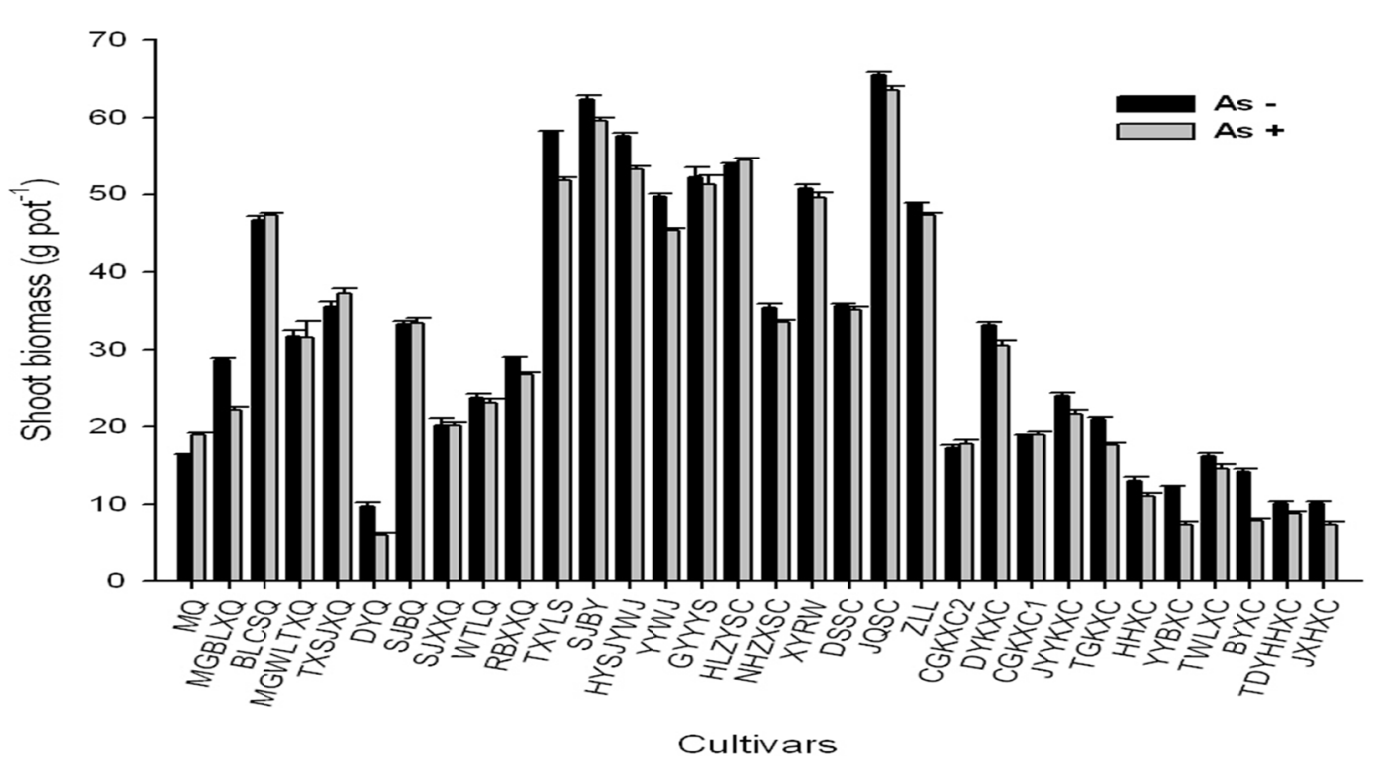

Figure 2. Shoot biomass of 32 cultivars exposed to $6 \mathrm{mg} \mathrm{L}^{-1}$ As for 14 days

Data are expressed as means \pm S.E. of four replicates. $p<0.05$ 


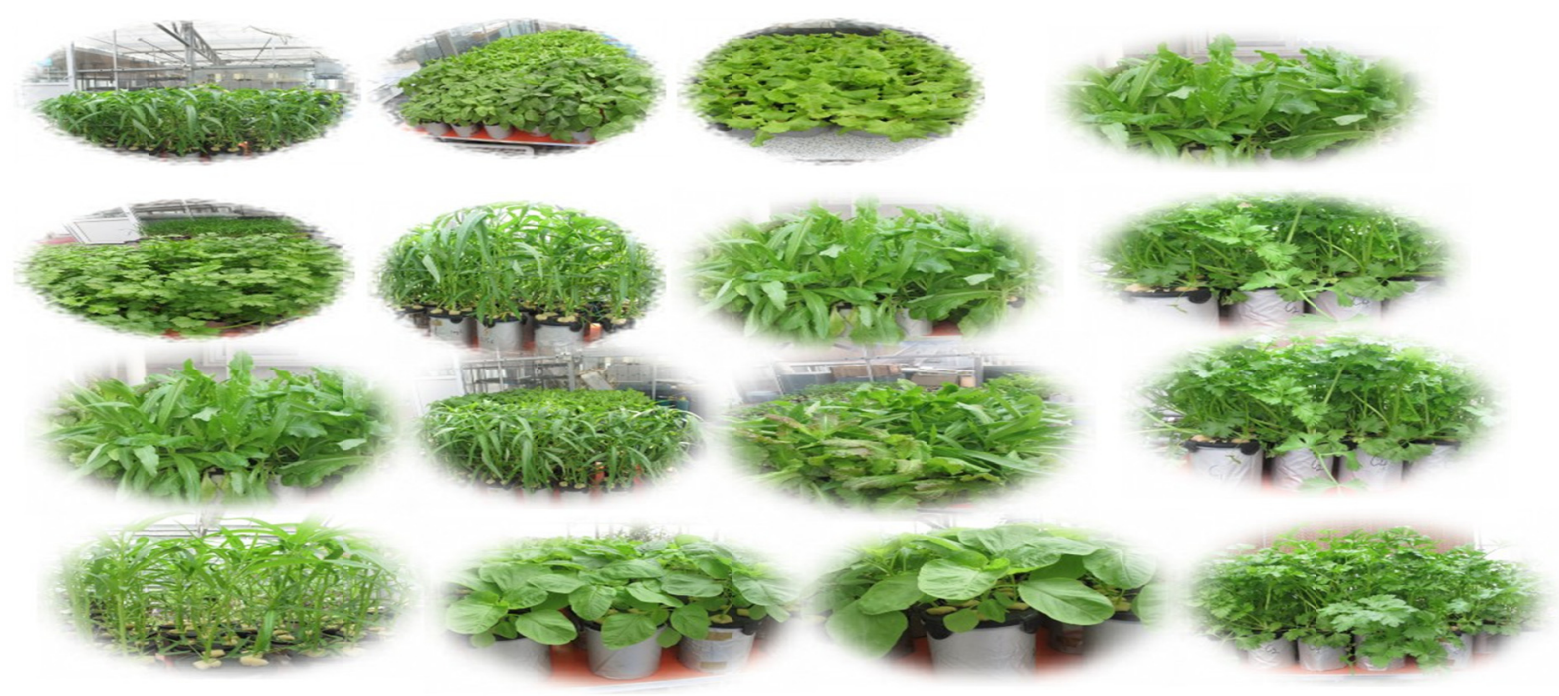

Figure 3 . The growth of leafy vegetable response to As stress

Table 3. Tolerance index (TI) based on shoot biomass of 32 different leafy vegetable cultivars exposed to $6 \mathrm{mg}$ $\mathrm{L}^{-1}$ As for 14 days.

\begin{tabular}{ll}
\hline Cultivar & Tolerance index \\
\hline Celery & $1.10 \pm 0.05 \mathrm{a}$ \\
Mei qin & $0.74 \pm 0.03 \mathrm{k}$ \\
Meiguo baili xiqin & $1.00 \pm 0.01 \mathrm{bcde}$ \\
Boli cui shi qin & $0.97 \pm 0.14 \mathrm{bcdefgh}$ \\
Meiguo wentu la xi qin & $1.02 \pm 0.05 \mathrm{bc}$ \\
Texuan si ji xi qin & $0.52 \pm 0.08 \mathrm{~m}$ \\
Daye qin & $0.98 \pm 0.02 \mathrm{bcdefg}$ \\
Shengjie bai qin & $0.95 \pm 0.04$ cdefghi \\
Siji xiao xiang qin & $0.93 \pm 0.03$ defghi \\
Wentula qin & $0.89 \pm 0.02$ ghij \\
Riben xiao xiang qin & \\
Lettuce & $0.89 \pm 0.02 \mathrm{hij}$ \\
Texuanyanling sun & $0.96 \pm 0.02 \mathrm{bcdefghi}$ \\
Sijibaiye & $0.92 \pm 0.02 \mathrm{efghij}$ \\
Huayesun jing yong woju & $0.92 \pm 0.01 \mathrm{efghij}$ \\
Yeyong woju & $0.98 \pm 0.02 \mathrm{bcdef}$ \\
Guayuanyiyesun & \\
Romaine & $1.01 \pm 0.02 \mathrm{bcd}$ \\
Helanziye shengcai & $0.95 \pm 0.04 \mathrm{cdefghi}$ \\
Nanhan zixiushengcai & $0.98 \pm 0.02 \mathrm{bcdef}$ \\
Xingyun ruan wei & $0.99 \pm 0.02 \mathrm{bcde}$ \\
Dasushengcai & $0.97 \pm 0.02 \mathrm{bcdefgh}$ \\
Jieqiushengcai & $0.97 \pm 0.01 \mathrm{bcdefgh}$ \\
Ziluolan &
\end{tabular}




\section{Water spinach}

Chunguo kongxincai2

Dayekongxincai

Chunguo kongxincai 1

Jingyanye kongxincai

Taiguo kongxincai

\section{Amaranth}

Huahongxianxcai

Yuanyebaixiancai

Taiwanluxiancai

Baiyexiancai

Tedayehuahongxiancai

Jingxuanhongxiancai
$1.04 \pm 0.06 \mathrm{ab}$

$0.92 \pm 0.05$ efghij

$1.01 \pm 0.05 \mathrm{bcd}$

$0.90 \pm 0.06$ fghij

$0.84 \pm 0.04 \mathrm{j}$

$0.85 \pm 0.04 \mathrm{j}$

$0.61 \pm 0.071$

$0.90 \pm 0.08$ fghij

$0.56 \pm 0.04 \mathrm{ln}$

$0.88 \pm 0.05 \mathrm{ij}$

$0.74 \pm 0.10 \mathrm{k}$

Values (mean \pm S.E., $\mathrm{n}=4$ with different letters in the same column are significantly different according to the Duncan's test $(\mathrm{P}<0.05)$

\subsection{Genetic Variations in Root-to-Shoot Transport and Nutrient Solution-to-Plant}

\subsubsection{Translocation Factor (TF)}

The TF can be used to evaluate the ability of the plant to translocate arsenic from the root to shoot. As shown in table (4), the average TF differed greatly among cultivars $(p<0.05)$. The root-shoot translocation factor ranging from 0.010 to 0.251 . The lowest TF was found in DYQ while RBXXQ showed the highest TF, similar to As accumulation. The results revealed twenty five fold genotypic variation in root- shoot translocation ability. In addition, among 32 cultivars, the TFs of 12 cultivars were not significantly different. The translocation factor (TF) was calculated by dividing the As concentration in the shoot by its concentration in the root.

\subsubsection{Bioaccumulation factor (BCF)}

The quotient of the As concentration in shoot to that in nutrient solution can be used to evaluate the ability of plants to accumulate heavy metals. Table 4 shows the average BCF of 32 cultivars under As treatment (6 mg L-1), ranging from 2.34 to $2.95,2.82$ to $4.51,4.92$ to $12.83,3.573$ to $7.965,15.25$ to 18.695 for lettuce, romaine, celery, amaranth and water spinach, respectively. The lowest BCF was found in lettuce (SJBY cultivar) and the highest BC was detected in water spinach (DYKXC cultivar), which was up 18.695. 
Table 4. Average TF and BCF of 32 selected leafy vegetable genotypes exposed to $6 \mathrm{mg} \mathrm{L}^{-1} \mathrm{As}$

\begin{tabular}{|c|c|c|}
\hline Genotypes & BCF & TF \\
\hline \multicolumn{3}{|l|}{ Celery } \\
\hline Mei qin & $9.42 \mathrm{ef}$ & $0.13 \mathrm{bc}$ \\
\hline Meiguo baili xiqin & $14.58 \mathrm{c}$ & $0.15 \mathrm{ab}$ \\
\hline Boli cui shi qin & $7.12 \mathrm{efgh}$ & 0.10 cde \\
\hline Meiguo wentu la xi qin & 5.62 ghijk & $0.02 \mathrm{~nm}$ \\
\hline Texuan si ji xi qin & $10.17 \mathrm{de}$ & $0.08 \mathrm{efgh}$ \\
\hline Daye qin & 4.92 ghijk & $0.01 \mathrm{~m}$ \\
\hline Shengjie bai qin & 6.36 fghij & 0.05 ghijkln \\
\hline Siji xiao xiang qin & $12.86 \mathrm{~cd}$ & 0.09 def \\
\hline Wentula qin & $12.85 \mathrm{~cd}$ & $0.16 \mathrm{ab}$ \\
\hline Riben xiao xiang qin & $12.87 \mathrm{~cd}$ & $0.17 \mathrm{a}$ \\
\hline \multicolumn{3}{|l|}{ Lettuce } \\
\hline Texuanyanling sun & $3.43 \mathrm{ijk}$ & 0.08 efg \\
\hline Sijibaiye & $2.34 \mathrm{k}$ & $0.03 \mathrm{klnm}$ \\
\hline Huayesun jing yong woju & $2.71 \mathrm{k}$ & $0.04 \mathrm{jklnm}$ \\
\hline Yeyong woju & $2.95 \mathrm{jk}$ & $0.04 \mathrm{jklnm}$ \\
\hline Guayuanyiyesun & $2.71 \mathrm{k}$ & $0.03 \mathrm{klnm}$ \\
\hline \multicolumn{3}{|l|}{ Romaine } \\
\hline Helanziye shengcai & 4.51 hijk & $0.03 \mathrm{klnm}$ \\
\hline Nanhan zixiushengcai & $3.42 \mathrm{ijk}$ & $0.03 \mathrm{lnm}$ \\
\hline Xingyun ruan wei & $2.82 \mathrm{jk}$ & $0.02 \mathrm{~nm}$ \\
\hline Dasushengcai & 4.27 hijk & 0.05 ghijkln \\
\hline Jieqiushengcai & $2.96 \mathrm{jk}$ & $0.04 \mathrm{ijklnm}$ \\
\hline Ziluolan & 4.32 hijk & $0.04 \mathrm{jklnm}$ \\
\hline \multicolumn{3}{|l|}{ Water Spinach } \\
\hline Chunguo kongxincai2 & $16.07 \mathrm{abc}$ & 0.07 fghij \\
\hline Dayekongxincai & $18.70 \mathrm{a}$ & $0.09 \mathrm{def}$ \\
\hline Chunguo kongxincai 1 & $15.74 \mathrm{abc}$ & 0.05 hijkln \\
\hline Jingyanye kongxincai & $18.40 \mathrm{ab}$ & $0.13 \mathrm{bc}$ \\
\hline Taiguo kongxincai & $15.25 \mathrm{bc}$ & 0.07 efghi \\
\hline \multicolumn{3}{|l|}{ Amaranth } \\
\hline Huahongxianxcai & $7.97 \mathrm{efg}$ & $0.13 \mathrm{bc}$ \\
\hline Yuanyebaixiancai & 3.77 hijk & 0.05 ghijkln \\
\hline Taiwanluxiancai & 6.75 fghi & $0.12 \mathrm{~cd}$ \\
\hline Baiyexiancai & 5.10 ghijk & 0.06 fghijk \\
\hline Tedayehuahongxiancai & 3.73 hijk & 0.06 fghijkl \\
\hline Jingxuanhongxiancai & $3.57 \mathrm{ijk}$ & $0.04 \mathrm{ijklnm}$ \\
\hline
\end{tabular}

Different letters in a colomn indicate significant differences between the cultivars at the 0.05 level

\subsection{Depletion of As concentration in nutrient solution}

The uptake time is one of the most important factors affecting the uptake of heavy metals by plants. Short-term, time-dependent arsenic depletion from hydroponic solution was measured at a series of different time intervals 
(after $0,0.5,1,2,4,6,8,10,12,22$ and $24 \mathrm{~h}$ ) and various concentration of arsenic. As shown in Figure 4, the depletion of As in TXYLS was higher for at least 12 hours and then starts to decrease rapidly with the passage of time until 24 hours, while SJBY was higher at the first 10 hours then starts decreasing until 24 hours. It can be explained that arsenic was absorbed by cultivars. Both the cultivars and treatments influenced concentrations of As in nutrient solution. At the end of the depletion $(24 \mathrm{~h})$, SJBY and TXYLS have up taken $23.09 \%$ and $28.40 \%$ of arsenic from nutrient solution, respectively (Figure 4). Interaction between treatments and cultivars influenced depletion of As concentration.
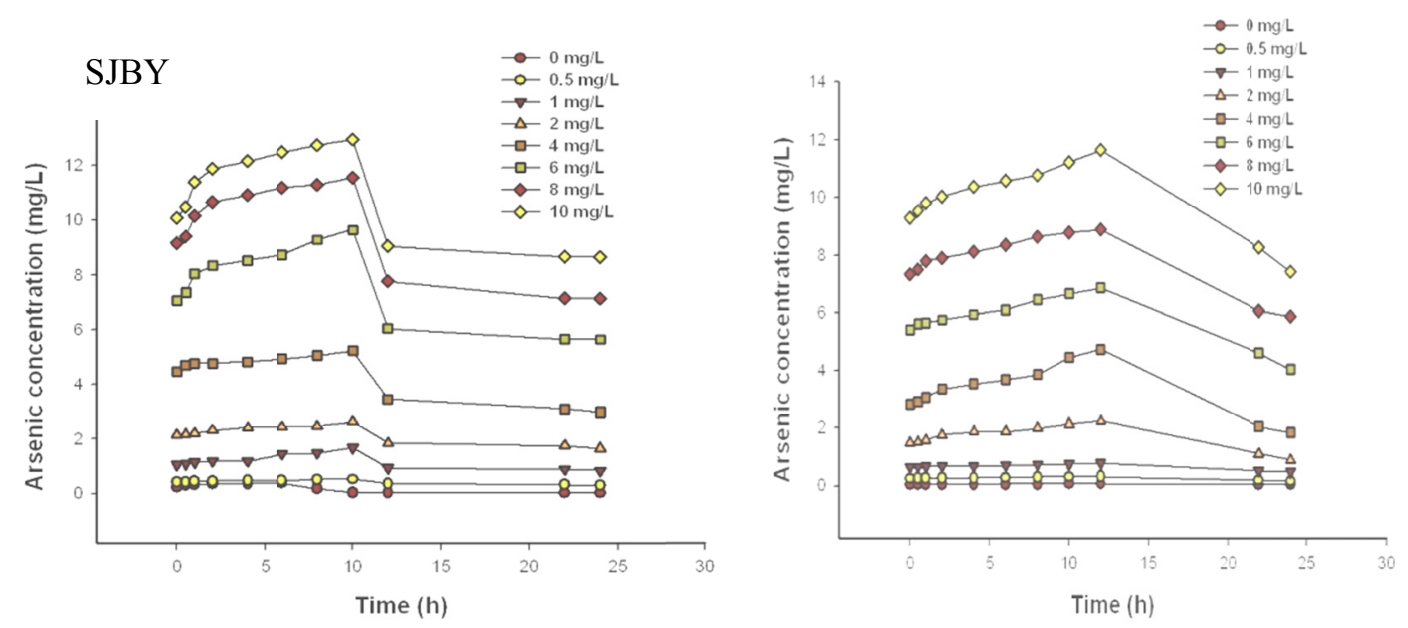

Figure 4. Depletion of As concentration $\left(\mathrm{mg} \mathrm{L}^{-1}\right)$ with time $(\mathrm{h})$ in the cultivars with high and low-As Accumulation (TXYLS and SJBY)

\subsection{Short-term Arsenic Uptake Kinetics}

The data for kinetic parameters which were derived from a linear regression on Lineweaver-Burk plot transformations are shown in table 5 and indicated that the uptake characteristics were different between cultivars. values of $\mathrm{Km}$ and Vmax were found to be much lower in SJBY $\left(26.721 \mathrm{mg} \mathrm{L}^{-1}\right.$ and $0.7737 \mathrm{mgAsg}-1$ shoot d.wt.hr ${ }^{-1}$ ) than that of TXYLS (81.922 $\mathrm{mg} \mathrm{L}^{-1}$ and $1.8488 \mathrm{mgAsg}^{-1}$ shoot d.wt.hr ${ }^{-1}$ ), indicating SJBY had the lowest uptake ability than TXYLS plants. Furthermore, TXYLS had the highest Km value than SJBY, confirming that uptake in the plant cell plasma membrane of TXYLS has a higher affinity for As than SJBY plants. The Vmax/Km values (Table 5) indicated that the arsenic uptake ability of cultivars followed TXYLS $>$ SJBY. Therefore, we could conclude that TXYLS's cell wall had a relatively strong arsenic binding capacity, while SJBY had relatively lower.

Table 5. Comparison in the low-As-accumulating cultivar 'SJBY' and the high-As-accumulating cultivar 'TXYLS' in kinetic parameters (Km, Vmax and $\mathrm{Km} / \mathrm{Vmax}$ ) for concentration-dependent uptake of As into intact plants immediately after $24 \mathrm{~h}$ of As exposure

\begin{tabular}{lllll}
\hline Cultivar & $\mathrm{V}_{\max }\left(\mathrm{mg}\right.$ As g-1 shoot d.wt.hr $\left.{ }^{-1}\right)$ & $\mathrm{K}_{\mathrm{m}}(\mathrm{mg} / \mathrm{L})$ & $\mathrm{K}_{\mathrm{m}} / \mathrm{V}_{\max }$ & $\mathrm{R}^{2}$ \\
\hline TXYLS & 1.848 & 81.922 & 44.312 & 1 \\
SJBY & 0.773 & 26.721 & 34.537 & 0.999 \\
\hline
\end{tabular}

\section{Discussion}

\subsection{Genetic Variations in As Concentration among Cultivars}

The uptake of heavy metal/metalloid in plants differs greatly, not only among plant species but also among cultivars within the same species. In this study, the results showed that with uniform arsenic treatment $\left(6 \mathrm{mg} \mathrm{L}^{-1}\right)$, wide genetic variations of As concentration was found among 32 tested leafy vegetable cultivars, revealing 6-8 fold variation ranged from 14.07 to $112.16 \mathrm{mg} \mathrm{kg}^{-1} \mathrm{~d}$.wt in shoot As concentration (Table 2). This finding is consistent with earlier observations by Delowar et al. (2005) and Williams et al. (2006). The lower As concentrations were observed in the shoots of all cultivars and increased in the roots (Figure 1), this could be due 
to the inability of plant to translocate As beyond the roots (Smith et al., 2009). These results reveal that genetic variability for As accumulation exists within a species/cultivar. It can be concluded that this large genotypic variation in shoot As concentrations shows that there are opportunities to select for low As cultivars As and to breed cultivars that can be used in contaminated agricultural land.

In this study, three groups of species could be differentiated, species with low, intermediate, and high shoot As concentration (Figure 1). The reasons for differences in As concentration in these species might be greater ability of As uptake, translocation ability and high biomass. For example, in this study water spinach and celery species had the ability to accumulate more arsenic with average concentrations of $100.97 \mathrm{mg} \mathrm{kg}^{-1}$ and $58 \mathrm{mg} \mathrm{kg}^{-1}$ in their shoots. Our results are consistent with others studies who have indicated that leafy vegetable spinach contained higher concentrations of As in shoots (Shaibur et al., 2009). Moreover, people may intake much amount of As without knowing the presence of high As in the vegetable. However, among 5 group of species, lettuce had the lowest average shoot As concentration $\left(16.95 \mathrm{mg} \mathrm{kg}^{-1} \mathrm{dw}\right)$ followed by romaine $\left(22.28 \mathrm{mg} \mathrm{kg}^{-1}\right)$ and amaranth (30.87 mg kg-1), similar trend was observed with other studies, Warren et al. (2003) detected 6.8 and $17.8 \mathrm{mg}$ $\mathrm{kg}^{-1} \mathrm{dw}$ in lettuce grown in soil that received As. In addition, Munoz et al. (2002) also reported a lower range of As concentrations in lettuce ( 0.68 to $4.5 \mathrm{mg} \mathrm{kg}^{-1} \mathrm{dw}$.). Therefore, high As concentrations in the root and low translocation to the shoot in these group species may suggest that leafy vegetable cultivars had a high tolerance to As and it mainly accumulates As in the root. On the other hand, water spinach group species had the highest average shoot As concentration (100.97 mg kg$)$ followed by celery $\left(58.059 \mathrm{mg} \mathrm{kg}^{-1}\right)$ when compared to other group species, which visibly demonstrate that the translocation of As was higher from the root to the shoot, which suggest that these species should be examined for phytoremediation potential.

In this study, the results indicated that cultivar was the key factor controlling the As transport into shoot and may lead to a large variation in leafy vegetable cultivars. Zia et al. (2011) found that As concentration in rice grain was affected by soil type ( $69 \%$ and $80 \%)$, followed by genotype ( $9 \%$ and $10 \%)$, among 38 rice varieties. Our results demonstrated that, leafy vegetable uptake might depend on vegetable cultivar and the rate of arsenic concentration under hydroponics.

\subsection{Growth Response of Vegetable to As Toxicity}

Under the same arsenic level, all cultivars seemed healthy, green and still alive and without showing any toxic symptoms (Figure 3), except for visible growth reductions. For most of the tested cultivars $(69 \%)$ showed a tolerance index higher than $90 \%$; this result indicates that leafy vegetable had considerable tolerance to As. In this study, the shoot biomass and TI were used as indicators to evaluate As toxicity to leafy vegetable. The results showed that almost all cultivars produced greater or similar shoot biomass except DYQ, YYBXC and BYXC, were able to cope up with $6 \mathrm{mg} \mathrm{L}^{-1}$ As stress with the maximum reduction less than $50 \%$ (Table 3). This dose $\left(6 \mathrm{mg} \mathrm{L}^{-1}\right)$ is much higher than normal As level in the Chinese soils and in heavily contaminated soils. Therefore, it is possible to grow leafy vegetable in As contaminated agricultural land. Consequently, farmers may not get sufficient warning about the toxic concentration of As in leafy vegetable based on yield change alone.

\subsection{The Important Factors Affecting As Uptake by Cultivars}

In this study, the transport of As from nutrient solution to root and shoot of the cultivars, different acquisition abilities of root for As, variation in the capability to absord As and accumulation abilty were the main important factors which resulted in cultivar difference. The results revealed that all the cultivars had TFs less than 1, (17 fold variation) and ( 8 fold) in BCF, indicating that As was limitedly transported into the shoot. Therefore, these leafy vegetable cultivars can be considered as a As excluder (Baker and Whiting, 2002), comprising avoidance of metal uptake and restriction of metal transport to the shoots. This is consistent with the results reported by Huang et al. (2005) using lettuce and when compared with other plants such as Pteris vittata (Francesconi et al.,2002), the As concentrations were high in the shoot (aboveground) than in root, also the TFs were greater than 1.0. Wei et al. (2005) found that the exclusion of metals from shoot has been regarded as a metal tolerant strategy. Metals, once taken up by roots, can either be stored in the roots or exported to the shoot.

\section{4 Identification of Genotypes with Low-As Uptake}

Hydroponic identification has the advantage of rapidness, environmental control, and repetitiveness, which is optimal for screening a large number of cultivars. However the identification in field provides direct evaluation, but it is time-consuming and costly (She et al., 2011). Hydroponic has already proved useful for screening interesting properties in plants (i.e., arsenic tolerance or accumulation), and the result can be confidently extrapolated to field conditions (Moreno et al., 2010). An important aspect of this study was to establish a screening and identification system for cultivars with the ability to accumulate less As in shoot that would be 
applicable on uniform arsenic-contaminated farmland. It should be noted that up to now, there is no scientific rules for hydroponics screening of cultivars like leafy vegetable that could be applied to identify suitable cultivars. To our knowledge, the number of hydroponic tests performed to study low As accumulation in shoot among different leafy vegetable species/cultivars is rather small and most of studies have been investigated on As hyperaccumulation. Results are therefore hardly comparable between different experiments and different species.

Screening of cultivars to be grown on contaminated farmland involves several criteria which may vary, but generally include consideration of tolerance and accumulating ability of the cultivar in response to the specific metal (Liu et al., 2009). Based on the previous literature and our research, we proposed three rules that were selected as a criterion. (1) Tolerance property, (2) As translocation factor and (3) lower As concentration in their shoots. It is well-known that some plants can grow in heavy metal contaminated soils without accumulating significant amounts. These types of plants are called excluders. Besides, Baker and whiting (2002), suggested that excluders can be characterized by TF less than 1.0, whereas in accumulators TF is more than 1.0. Therefore, due to the different growing environments, the same rules use in this study may have different effectiveness in field and pot identifications. Based on the average shoot As concentration among 5 group of species, water spinach appears to be relatively high accumulator of As and thus it could be argued that this species could probably not be suitable to be grown on farmland with elevated As level. Celery also exhibited relatively high accumulation concentration and should probably be avoided on As-contaminated soils. On the other hand, lettuce and romaine species appear to accumulate less As concentration and so would be suitable species to grow. Amaranth had intermediate As concentration, but the significant differences among cultivars and the arsenic uptake ability based on kinetic parameters indicate that SJBY is the most suitable for minimizing As intake on As contaminated soils. When shoot/root quotient (TF) was taken into account, according to Baker and Whiting (2002) who suggested that excluders are characterized with TF $<1.0$, as showed in table 3-5, all the cultivars had TFs $<1.0$ and thus 12 cultivars were significantly lower than other cultivars. However there were selected as suitable cultivars. we also tried to confirm regarding to their tolerance to As stress; most of the tested cultivars $(69 \%)$ were tolerant showed a tolerance index higher than $90 \%$, thus, only two cultivars was identified to high TI compared to others and when BCF was further considered, 17 cultivars appeared to have significantly lower $\mathrm{BCF}$ than other species. In general, if the tolerance to As stress, arsenic concentration, $\mathrm{TF}, \mathrm{BF}$ are all considered in the study, lettuce species (e.g SJBY) was the most appropriate cultivar for planting in arsenic contaminated farmland.

\section{Conclusion}

A hydroponics screening methodology was used in this study to screen and identify cultivars for low-As concentration ability in order to be grown on arsenic contaminated farmland. The results obtained exibit the existence of genotypic variations in the shoot As concentration among 32 cultivars under arsenic treatment (6 $\mathrm{mg} / \mathrm{L}$ ). Distinctive differences were also identified when comparing species to another. Lettuce and romaine species tending to be low accumulators, amaranth species tending to be moderate accumulator, and water spinach being high accumulator. The TFs of all cultivars were lower than 1.0. This detailed study was effective in providing complete information regarding the variation of arsenic concentration and accumulation in different cultivars based on the results from hydroponics.

It can be also concluded that our results could aid rapid development of leafy vegetable genotypes with decrease As accumulation in shoot by selection and bredding techniques while great care is needed for using lettuce cultivars. The selected cultivars had considerable tolerance to As according to their shoot biomass, except in DYQ and BYXC.Thus these cultivars can be cultivated in arsenic contaminated areas without any major risk of significant, considering the shoot biomass alone. Based on the hydroponic experiment alone, SJBY could be finally identified as suitable cultivar to be grown on arsenic contaminated farmland with low arsenic contaminated soil.

These results suggested that the uptake, translocation and accumulation of As in the cultivars may be strongly linked to genetics and associated to As concentrations in the plant, cultivars differences and the retention of As in the roots. Therefore, it seemed worthwhile to carry out similar screening tests with a larger number of cultivars of other species. In addition, further research comparing the different leafy vegetables under hydroponics, pot condition and field condition would be of great interest.

\section{Acknowledgements}

This study is a part of a research project. Thanks should be given to Dr Shuming and Dr Li LIANFANG for their assistance in the laboratory experiments, data analysis and manuscript preparation. This study was financially 
supported by the National Scientific and Technological Program of the "12th Five-Year" Plan of China (Grant No. 2012BAD14B02), and the National Natural Science Foundation of China (Grant No.41171255).

\section{References}

Ajaelu, C. J., Ibironke, Oluwafunke, L., Adedeji, V., \& Olafisoye, O. (2011). Equilibrium and Kinetic Studies of the Biosorption of Heavy Metal (Cadmium) on Cassia siamea Bark. American-Eurasian Journal of Scientific Research, 6, 123-130.

Baker, A. J. M., \& Whiting, S. N. (2002). In search of the Holy Grail - a further step in understanding metal hyperaccumulation. New Phytologist, 155, 1-7. http://dx.doi.org/10.1046/j.1469-8137.2002.00449_1.x

Delowar, H. K. M., Yoshida, I., \& Harada, M. (2005). Growth and uptake of arsenic by rice irrigated with As-contaminated water. Journal of Food Agriculture and Environment, 3, 287- 291.

Francesconi, K., Visoottivieth, P., Sridokchan, W., \& Goessler, W. (2002). Arsenic species in an arsenic hyper accumulating fern, Pityrogramma calomelanos: a potential phytoremediation of arsenic-contaminated soils. Science of the Total Environment, 284, 27-35. http://dx.doi.org/10.1016/S0048-9697(01)00854-3

Glass, A. D. M. (1989). Plant nutrition: An introduction to current concepts. Boston, MA, USA: Jones and Bartlett Publishers. p. 234.

Huang, B., Kuo, S., \& Bembenek, R. (2005). Availability to Lettuce of Arsenic and Lead from Trace Element Fertilizers in Soil. Water Air and Soil Pollution, 164, 223-239. http://dx.doi.org/10.1007/s11270-005-3023-6

Islam, E., Yang, X., He, Z., \& Mahmood, Q. (2007). Assessing potential dietary toxicity of heavy metals in selected vegetables and food crops. Journal of Zheijang University Science B, 8, 1-13. http://dx.doi.org/10.1631/jzus.2007.B0001

Lineweaver, H., \& Burk, D. (1934). The determination of enzyme dissociation constants. American Chemical Society, 56, 658-666. http://dx.doi.org/10.1021/ja01318a036

Liu, W. T., Zhou, Q. X., \& Jing, A. (2009). Variations in cadmium accumulation among Chinese cabbage cultivars and screening for Cd- safe cultivars. Journal of Hazardous Materials, 8, 14-147.

McGrath, S. P., Zhao, F. J., \& Lombi, E. (2001). Plant and rhizosphere process involved in phytoremediation of metal-contaminated soils. Plant and Soil, 232, 207-214. http://dx.doi.org/10.1023/A:1010358708525

Meharg, A. A., \& Hartley, W. J. (2002). Arsenic uptake and metabolism in arsenic resistant and nonresistant plant species. New Phytologist, 154, 29-43. http://dx.doi.org/10.1046/j.1469-8137.2002.00363.x

Moreno, J. E., Esteban, E., Fresno, T., Egea, C. L., \& Penalosa, J. M. (2010). Hydroponics as a valid tool to assess arsenic availability in mine soils. Chemosphere, 79, 513-517. http://dx.doi.org/10.1016/j.chemosphere.2010.02.034

Munǒz, O., Diaz, O. P., Leyton, I., Nuñez, N., Devesa, V., \& Súñer, M. A. (2002). Vegetables collected in the cultivated Andean area of northern Chile: Total and inorganic arsenic content in raw vegetables. Journal of Agricultural and Food Chemistry, 50, 642-647. http://dx.doi.org/10.1021/jf011027k

Norton, G. J., Pinson, S. R. M., Alexander, J., Mckay, S., Hansen, H., \& Duan, G. L. (2012). Variation in grain arsenic assessed in a diverse panel of rice (Oryza sativa) grown in multiple sites. New Phytologist, 193, 650-664. http://dx.doi.org/10.1111/j.1469-8137.2011.03983.x

Norton, G. J., Duan, G. L., Dasgupta, T., Islam, M. R., Lei, M.,Zhu, Y. G., et al. (2009). Environmental and genetic control of arsenic accumulation and speciation in rice grain: Comparing a range of common cultivars grown in contaminated sites across Bangladesh, China, and India. Environmental Science \& Technology, 43, 8381-8386. http://dx.doi.org/10.1021/es901844q

Shaibur, M. R., \& Kawai, S. (2009). Effect of arsenic on visible symptom and arsenic concentration in hydroponic Japanese mustard spinach. Environmental and Experimental Botany, 67, 65-70. http://dx.doi.org/10.1016/j.envexpbot.2009.06.001

She, W., Jieyu, C., Xing, H. C., Wei, Y. L., Huang, M., \& Li, W. K. (2011). Tolerance to Cadmium in Ramie (Boehmeria nivea Genotypes and Its Evaluations Indicators). Acta Agriculturae Sinica, 424(37), 348-354.

Smith, E., Juhasz, A. L., \& Weber, J. (2009). Arsenic uptake and speciation in vegetables grown under greenhouse conditions. Environmental Geochemistry and Health, 31, 125-132. http://dx.doi.org/10.1007/s10653-008-9242-1

Warren, G. P., Alloway, B. J., \& Lepp, N. W. (2003). Field trial to assess the uptake of arsenic by vegetables 
from contaminated soil and soil remediation with iron oxides. Science of the Total Environment, 311, 19-33. http://dx.doi.org/10.1016/S0048-9697(03)00096-2

Wei, S. H., Zhou, Q. X., \& Wang, X. (2005). Identification of weed plants excluding the absorption of heavy metals. Environment International, 31, 829-834. http://dx.doi.org/10.1016/j.envint.2005.05.045

Williams, P. N., Islam, M. R., Raab, A., Hossain, S. A., \& Meharg, A. A. (2006). Increase in rice grain arsenic for regions of Bangladesh irrigating paddies with elevated arsenic in groundwater.

Zia, U. A., Golam, M. P., Hugh, G. J., Susan, R. M., Wricha, T. I., Mohammed, S., \& John, M. D. (2011). Genotype and environment effects on rice (Oryza sativa L.) grain arsenic concentration in Bangladesh. Plant and Soil, 338, 367-382. http://dx.doi.org/10.1007/s11104-010-0551-7

\section{Copyrights}

Copyright for this article is retained by the author(s), with first publication rights granted to the journal.

This is an open-access article distributed under the terms and conditions of the Creative Commons Attribution license (http://creativecommons.org/licenses/by/3.0/). 